\title{
Mechanisms of ferroptosis
}

\author{
Jennifer Yinuo Cao ${ }^{1} \cdot$ Scott J. Dixon ${ }^{1}$
}

Received: 14 March 2016/Accepted: 18 March 2016/Published online: 5 April 2016

(c) The Author(s) 2016. This article is published with open access at Springerlink.com

\begin{abstract}
Ferroptosis is a non-apoptotic form of cell death that can be triggered by small molecules or conditions that inhibit glutathione biosynthesis or the glutathione-dependent antioxidant enzyme glutathione peroxidase 4 (GPX4). This lethal process is defined by the iron-dependent accumulation of lipid reactive oxygen species and depletion of plasma membrane polyunsaturated fatty acids. Cancer cells with high level RAS-RAF-MEK pathway activity or p53 expression may be sensitized to this process. Conversely, a number of small molecule inhibitors of ferroptosis have been identified, including ferrostatin-1 and liproxstatin-1, which can block pathological cell death events in brain, kidney and other tissues. Recent work has identified a number of genes required for ferroptosis, including those involved in lipid and amino acid metabolism. Outstanding questions include the relationship between ferroptosis and other forms of cell death, and whether activation or inhibition of ferroptosis can be exploited to achieve desirable therapeutic ends.
\end{abstract}

Keywords Cell death - Iron - Reactive oxygen species . Glutathione - Cancer - RAS - Glutathione peroxidase 4 . Erastin · Sorafenib · Ferrostatin-1 .

Polyunsaturated fatty acid

Scott J. Dixon

sjdixon@stanford.edu

1 Department of Biology, Stanford University, 337 Campus Dr., Stanford, CA 94305, USA

\section{Introduction}

Regulated cell death (RCD) is essential for normal development and the maintenance of homeostasis. RCD can proceed through apoptosis or one of several non-apoptotic cell death pathways, including the recently described process of ferroptosis [1-5]. Ferroptosis is an oxidative, irondependent form of cell death that is distinct from apoptosis, classic necrosis, autophagy and other forms of cell death [5] (Table 1). Ferroptosis is triggered by inactivation of cellular glutathione (GSH)-dependent antioxidant defenses, leading to the accumulation of toxic lipid ROS (L-ROS) [5, 6] (Fig. 1). This process has recently been implicated in the pathological cell death of brain tissues exposed to high levels of glutamate (Glu) as well as kidney and heart tissues subjected to ischemia-reperfusion injury [5, 7-10]. In the context of cancer, ferroptosis may act as an endogenous tumor suppressive mechanism downstream of p53 [11]. It may also be possible to use small molecule activators of ferroptosis to selectively eliminate cancer cells with mutations in the RAS-RAF-MEK pathway, although this remains controversial $[6,12,13]$. It is, therefore, of great interest to understand how this novel RCD pathway is regulated.

\section{The recognition of ferroptosis as a unique form of RCD}

The RAS family of small GTPases (HRAS, NRAS and KRAS) is commonly mutated in cancer and several groups have searched for small molecules that are selectively lethal to cells expressing oncogenic mutant RAS proteins $[12,14-16]$. In the 2000's, the Stockwell laboratory isolated two novel oncogenic RAS Selective Lethal (RSL) 


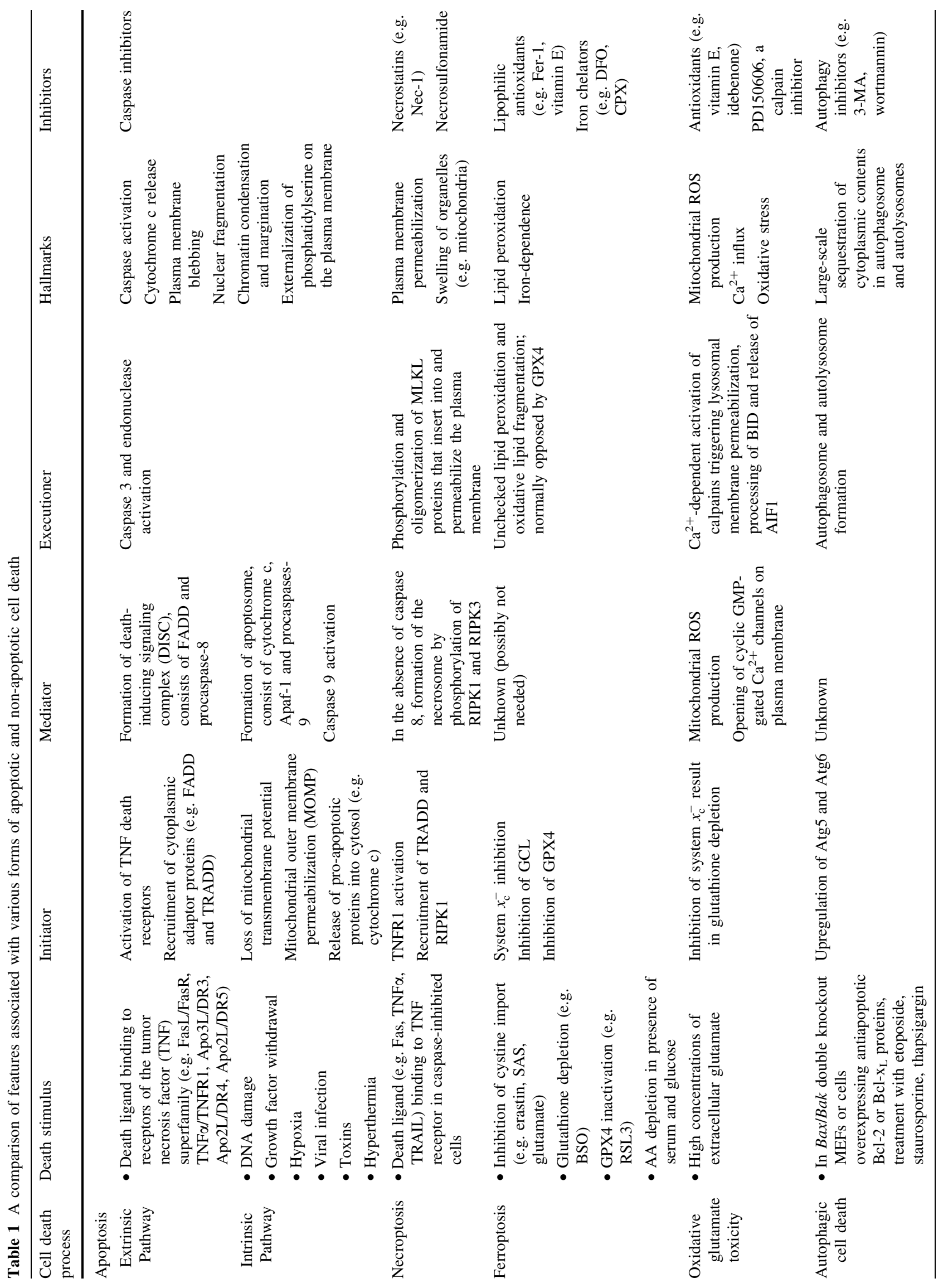


small molecules named eradicator of Ras and ST (erastin) and Ras Selective Lethal 3 (RSL3) (Fig. 2a, b) [12, 17]. Both compounds were lethal at lower doses in engineered human tumor cells expressing oncogenic HRAS ${ }^{\mathrm{V} 12}$ than in isogenic cells expressing wild-type HRAS $[12,17]$. The recognition of ferroptosis as a unique form of $\mathrm{RCD}$ emerged, unexpectedly, from characterizing the lethal mechanism of action of erastin and RSL3.

Erastin and RSL3 treatment do not trigger morphological changes or biochemical processes consistent with apoptosis, such as chromatin margination or cleavage of poly ADP-ribose polymerase (PARP) [12, 13, 17]. Moreover, erastin- and RSL3-induced cell death is not attenuated by caspase inhibition, by deletion of the intrinsic apoptotic effectors BCL-2 associated X protein (BAX) and BCL-2 antagonist/killer 1 (BAK), by a small molecule inhibitor of necroptosis (e.g. necrostatin-1) or by inhibition of autophagy (e.g. using chloroquine, 3-methyladenine) $[5,6,12,17,18]$. Neither mitochondrial ROS production nor the influx of $\mathrm{Ca}^{2+}$ is essential for ferroptosis [5]. However, erastin treatment results in a unique 'dysmorphic' mitochondrial phenotype observable by transmission electron microscopy [5]. Erastininduced cell death also depends on a unique set of genes compared to cell death or cytostasis triggered by proapoptotic or pro-necrotic agents [5]. Crucially, erastinand RSL3-induced cell death is effectively inhibited by the iron chelators DFO, 311, ciclopirox (CPX) and 2,2bipyridyl (2,2-BP), as well as by the lipophilic antioxidants trolox (a soluble vitamin $\mathrm{E}$ analog), butylated hydroxyanisole, butylated hydroxytoluene and the novel synthetic antioxidant ferrostatin-1 (Fer-1) [5, 13, 17] (Fig. 1). These results indicate that iron-dependent L-ROS accumulation is essential for erastin- and RSL3induced cell death. On this basis, the unique erastin- and RSL3-induced cell death phenotype was named 'ferroptosis' [5] (Table 1).

\section{Early studies informing our understanding of the ferroptotic mechanism}

The role of oxidative stress in cell death has been studied for some time. Pioneering studies in the 1950's by Harry Eagle and colleagues examined the amino acids, vitamins and other nutrients required to support the growth and proliferation of mammalian cells in culture [19]. Among those determined to be essential was cystine $\left(\mathrm{Cys}_{2}\right)$, the oxidized form of the thiol-containing amino acid cysteine (Cys) [19]. Cells deprived of $\mathrm{Cys}_{2}$ fail to grow unless cultured at extremely high densities [19-21]. Following up on these observations, in 1977 Shiro Banni and colleagues found that depriving 


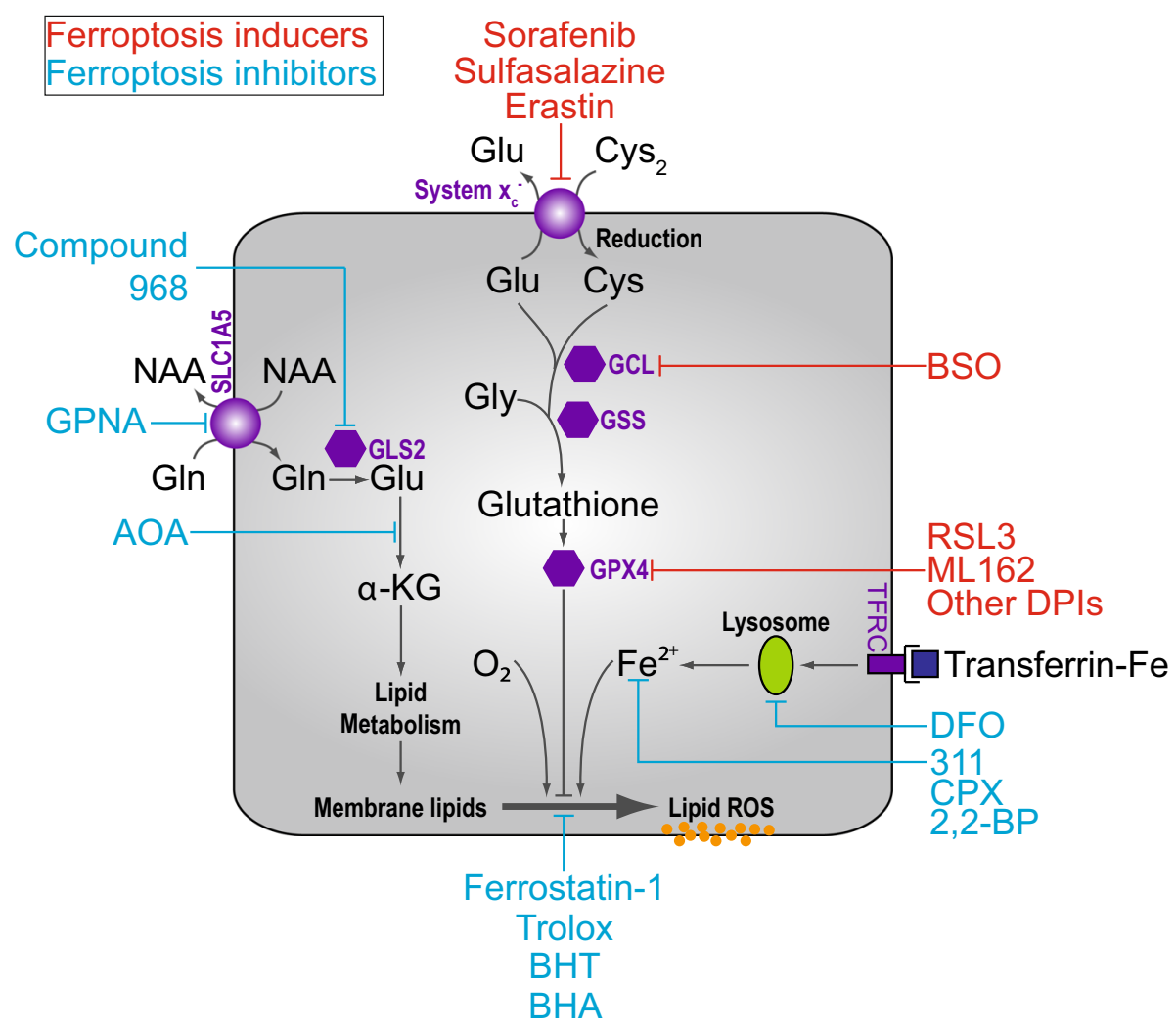

Fig. 1 Overview of the ferroptosis pathway. In many cells, cystine $\left(\mathrm{Cys}_{2}\right)$ import via system $x_{\mathrm{c}}^{-}$is required for glutathione synthesis, and the function of glutathione peroxidase 4 (GPX4). GPX4 activity prevents the accumulation of lipid ROS that are lethal to the cell. Treatment blocks cystine uptake, ultimately depleting the cell of glutathione and inhibiting the function of GPX4. Direct inhibition of the rate-limiting glutathione synthetic enzyme glutamate-cysteine ligase (GCL) using buthionine-( $S, R)$-sulfoximine (BSO) can also lead

cultured human lung fibroblasts of $\mathrm{Cys}_{2}$ resulted in rapid depletion of the Cys-containing antioxidant tripeptide GSH ( $\gamma$-L-glutamyl-L-cysteinylglycine), and subsequent cell death [22]. Cell death was prevented, without rescuing GSH levels, by growing cells in the presence of the lipophilic antioxidant $\alpha$-tocopherol (vitamin E) [22]. These results implied that $\mathrm{Cys}_{2}$ import was needed to sustain GSH levels, and that cell death was triggered by a buildup of L-ROS. In subsequent years, studies of $\mathrm{Cys}_{2}$ deprivation-induced cell death in human embryonic fibroblasts, neuronal hybridoma cells and rat oligodendrocytes confirmed the importance of GSH depletion in cell death, and demonstrated that both lipophilic antioxidants and iron chelators could block this process from occurring [23-26]. Collectively, these reports established that continuous $\mathrm{Cys}_{2}$ uptake and GSH synthesis are required in many types of mammalian cells to prevent the accumulation of toxic L-ROS and help frame our understanding of how erastin and RSL3 trigger ferroptosis at the molecular level. to the same iron- and ROS-dependent ferroptotic phenotype. Other small molecule inducers of ferroptosis are indicated in red, while suppressors of ferroptosis are in blue. GCL Glutamate cysteine ligase, GSS glutathione synthetase, Cys cysteine, Glu glutamate, Gly glycine, $G l n$ glutamine. $\alpha-K G$ alpha-ketoglutarate, GPNA L-g-glutamyl-pnitroanilide, $A O A$ amino oxyacetate, $B H A$ butylated hydroxyanisole, $B H T$ butylated hydroxytoluene, $D F O$ deferoxamine, 2,2-BP 2,2bipyridyl, $C P X$ ciclopirox

\section{Inhibition of system $x_{\mathrm{c}}^{-}$triggers ferroptosis}

Analysis of the erastin mechanism of action provided the first insights into proteins and pathways necessary to prevent the onset of ferroptosis. Early chemoproteomic studies using erastin analogs conjugated to a solid support matrix identified the mitochondrial voltage dependent anion channel 2 and 3 (VDAC2 and VDAC3) as direct erastin targets [13]. Experiments using purified human VDAC2 reconstituted into artificial liposomes confirm that erastin can bind this target and modulate transport flux [27]. However, it now appears that the ability of erastin to trigger ferroptosis is determined mainly by inhibition of a different target, the cystine/glutamate antiporter termed system $x_{\mathrm{c}}^{-}$[5, 28] (Fig. 1).

System $x_{\mathrm{c}}^{-}$is a heterodimeric cell surface amino acid antiporter composed of the twelve-pass transmembrane transporter protein SLC7A11 (xCT) linked by a disulfide bridge to the single-pass transmembrane regulatory protein SLC3A2 (4F2hc, CD98hc) [29]. System $x_{\mathrm{c}}^{-}$imports 
Fig. 2 Structure of small molecule ferroptosis inducers. a molecules that inhibit the function of system $x_{\mathrm{c}}^{-}$. b Molecules that inhibit the function of glutathione peroxidase 4 (GPX4). ML162 is also known as DPI7
A

<smiles>CNC(=O)c1cc(Oc2ccc(NC(=O)Nc3ccc(Cl)c(C(F)(F)F)c3)cc2)ccn1</smiles>

B<smiles>COC(=O)c1ccc([C@H]2C3Nc4ccccc4C3C[C@H](C(=O)OC)N2C(=O)CCl)cc1</smiles>

1S,3R-RSL3<smiles>Cc1onc(C(=O)N2CCN(C(c3ccc(Cl)cc3)c3ccc(Cl)cc3)CC2)c1[N+](=O)[O-]</smiles>

ML210 (DPI10)<smiles>COc1ccc(N(C(=O)CCl)C(C(=O)NCCc2ccccc2)c2cccs2)cc1Cl</smiles>

ML162 (DPI7)<smiles>CN(C)c1nc(N(C)C)nc(N(C)C)n1</smiles>

Altretamine extracellular $\mathrm{Cys}_{2}$ in exchange for intracellular Glu. Using 'modulatory profiling' (see [18]) it was found that cell death induced by erastin is similar in many respects to cell death induced by sulfasalazine (SAS) [5], a known system $x_{\mathrm{c}}^{-}$inhibitor [30] (Fig. 2a) (Table 2). Notably, the lethal effects of both SAS and erastin are reversed by co-treatment with $\beta$-mercaptoethanol ( $\beta$-ME) [5, 28], which bypasses the need for system $x_{\mathrm{c}}^{-}$, by forming mixed disulfides with $\mathrm{Cys}_{2}$ that can be imported into the cell by a different transporter [31]. Most convincingly, erastin and SAS block the uptake of radiolabelled $\mathrm{Cys}_{2}$ in cultured cancer cells $[5,28]$. Thus, erastin appears to act as a direct inhibitor of system $x_{\mathrm{c}}^{-}$function. This links the erastin mechanism of action to a process (Cys-dependent GSH synthesis) that normally opposes the accumulation of L-ROS. Indeed, erastin treatment leads to significant depletion of intracellular GSH, as detected using traditional biochemical methods and more advanced metabolomics analyses $[6,7,28]$. It is not known precisely how erastin or SAS inhibit SLC7A11-mediated Cys 2 import. It was initially proposed that erastin bound to a related transport protein, SLC7A5, and inhibited SLC7A11 in trans [5]. 
However, more recent data argue against this possibility, and suggest that erastin most likely inhibits SLC7A11 directly [28]. More potent and drug-like analogs of erastin have been described and should facilitate future studies of the targets and effects of erastin in vitro and in vivo $[6,28$, 32].

In addition to erastin and SAS, the FDA-approved multikinase inhibitor sorafenib (trade name: Nexavar) can block system $x_{\mathrm{c}}^{-}$function, deplete GSH and trigger ferroptosis in cancer cell lines derived from liver, kidney, bone, lung and other tissues [28, 33, 34] (Table 2) (Fig. 2a). Related kinase inhibitors have no ability to block system $x_{\mathrm{c}}^{-}$function or cause ferroptosis [28, 33], suggesting that the effects of sorafenib could be due either to modulation of a very specific kinase (that in turn modulates system $x_{\mathrm{c}}^{-}$ activity) or to a direct effect on system $x_{\mathrm{c}}^{-}$. This function may explain the ability of sorafenib to trigger caspaseindependent cell death in certain cell types and enhance ROS accumulation in sorafenib-treated cancer patients [35, 36]. Indeed, it is intriguing to speculate that the clinical benefit of sorafenib observed in patients may be due, at least in part, to the activation of ferroptosis in vivo [28]. However, the effects of this compound are clearly pleiotropic: in some cell lines sorafenib triggers apoptosis [37], and even in cell lines where ferroptosis is observed at low doses of sorafenib, apoptosis or some other form of cell death is observed at higher doses [28]. Further study is required to disentangle the various effects of sorafenib on the cell and determine whether the effects of this compound in patients are attributable to ferroptosis.

\section{The role of GPX4 in preventing ferroptosis}

Elucidation of the RSL3 mechanism of action provided the next major insight into the regulation of ferroptosis. Of the four possible RSL3 diastereomers, only one- $1 S, 3 R$ RSL3 -is capable of inducing ferroptosis [6] (Fig. 2B). Chemoproteomic studies using the active isomer of RSL3 as an affinity reagent identified the selenoprotein glutathione peroxidase 4 (GPX4, PHGPx) as a candidate target of this compound [6] (Fig. 1). GPX4 is a GSH-dependent enzyme that reduces lipid hydroperoxides (L$\mathrm{OOH}$ ) to lipid alcohols (L-OH). GPX4, therefore, normally limits the iron-dependent formation of highly reactive lipid alkoxy radicals (L-O) from L-OOH [38, 39]. Cells appear to be continually exposed to the threat of L-ROS-mediated destruction, as inhibition of GPX4 activity leads to the rapid accumulation of L-ROS and cell death in cell culture, and deletion of Gpx4 in mice is embryonic lethal [6,39]. Consistent with RSL3-mediated inactivation of GPX4 being essential to induce ferroptosis, overexpression of GPX4 blocks RSL3-induced cell death while short hairpin RNA (shRNA)-mediated knockdown of GPX4 in human oncogenic HRAS cells is sufficient to induce ferroptotic cell death [6]. Deletion of Gpx4 in mouse cells also results

Table 2 Examples of small molecule-induced ferroptosis

\begin{tabular}{|c|c|c|c|c|}
\hline Small molecule & Cell line & Target & Observation & References \\
\hline Erastin, sulfasalazine & $\begin{array}{l}\text { Engineered human tumor cells, } \\
\text { HT-1080, Calu-1, A-673, } \\
\text { Panc-1, other cancer cell } \\
\text { lines, isolated mouse renal } \\
\text { tubules }\end{array}$ & System $x_{\mathrm{c}}^{-}$ & $\begin{array}{l}\text { Death suppressed by iron chelators } \\
\text { (DFO, CPX), lipophilic } \\
\text { antioxidants (e.g. Fer-1, trolox, } \\
\text { vitamin E), the protein synthesis } \\
\text { inhibitor cycloheximide, the } \\
\text { reducing agent beta- } \\
\text { mercaptoethanol, the } \\
\text { transaminase inhibitor amino- } \\
\text { oxyacetate }\end{array}$ & $\begin{array}{l}\text { Dixon et al. [5], Linkermann } \\
\text { et al. [8], Dolma et al. [12], } \\
\text { Yagoda et al. [13], Eling } \\
\text { et al. [15], Yang and } \\
\text { Stockwell [17] }\end{array}$ \\
\hline Sorafenib & HT-1080, Huh7, ACHN & System $x_{\mathrm{c}}^{-}$ & Death suppressed by DFO, Fer-1 & $\begin{array}{l}\text { Dixon et al. [28], Lachaier et al. } \\
\text { [33], Louandre et al. [34] }\end{array}$ \\
\hline $\begin{array}{l}\text { 1S,3R-RSL3, DPI19, } \\
\text { DPI18, DPI17, DPI13, } \\
\text { DPI12, DPI10 } \\
\text { (ML210), DPI7 } \\
\text { (ML162), altretamine }\end{array}$ & $\begin{array}{l}\text { Engineered human tumor cells, } \\
\text { HT-1080, Calu-1, others }\end{array}$ & GPX4 & $\begin{array}{l}\text { Death suppressed by iron chelators } \\
(311, \text { DFO, CPX) and lipophilic } \\
\text { antioxidants (butylated } \\
\text { hydroxytoluene, trolox, vitamin } \\
\text { E, Fer-1) }\end{array}$ & $\begin{array}{l}\text { Yang et al. [6], Dixon et al. [5], } \\
\text { Yang and Stockwell [17], } \\
\text { Woo et al. [40] }\end{array}$ \\
\hline Artesunate & Panc-1 & $\begin{array}{l}\text { Possibly } \\
\text { lysosomal } \\
\text { iron; } \\
\text { unknown }\end{array}$ & $\begin{array}{l}\text { Death suppressed by lipophilic } \\
\text { antioxidant (Fer-1) and iron } \\
\text { chelation (DFO) }\end{array}$ & Eling et al. [15] \\
\hline $\begin{array}{l}\text { Buthionine- }(S, R) \text { - } \\
\text { sulfoximine }\end{array}$ & MEFs, HT-1080 & GCLC & $\begin{array}{l}\text { Death suppressed by lipophilic } \\
\text { antioxidant ( } \alpha \text {-tocopherol, Fer-1) } \\
\text { and iron chelation (DFO) }\end{array}$ & $\begin{array}{l}\text { Friedmann Angeli et al. [9], } \\
\text { Seiler et al. [39] }\end{array}$ \\
\hline
\end{tabular}

$M E F s$ mouse embryonic fibroblasts, $B S O$ buthionine-( $S, R)$-sulfoximine, $G C L C$ glutamate-cysteine ligase, catalytic subunit, $D F O$ deferoxamine 
in cell death that can be suppressed by lipophilic antioxidants (e.g. Fer-1) and iron chelators, further confirming that GPX4 activity is essential to prevent ferroptosis [9, 39].

In addition to RSL3, nine other synthetic small molecules, including ML162 (also known as DPI7), ML210 (also known as DPI10) and, most unexpectedly, the FDAapproved anticancer agent altretamine, can inhibit GPX4 activity [6, 16, 40] (Table 2; Fig. 2b). Like RSL3, these compounds inhibit GPX4 enzymatic activity without depleting the cell of glutathione. Thus, RSL3 and functionally related compounds are classified as "class 2" ferroptosis-inducing compounds (FINs), to distinguish them from erastin and other system $x_{\mathrm{c}}^{-}$inhibitors that that most likely block GPX4 function indirectly by preventing GSH synthesis ("class 1" FINs) [6, 40]. Mechanistically, how RSL3 and other class 2 FINs bind GPX4 to inhibit its activity is not known.

\section{Ferroptosis can be induced by glutathione depletion}

Ferroptosis can be induced by depriving cells of the essential GSH precursor, Cys, or by blocking the function of the GSH-dependent enzyme GPX4 (see above). Thus, direct inhibition of GSH synthesis would be predicted to trigger ferroptosis. Consistent with this prediction, inhibition of glutamate-cysteine ligase (GCL, formerly known as $\gamma$-glutamylcysteine synthetase), the rate-limiting first enzyme in the two-step synthesis of GSH, using buthionine-( $S, R)$-sulfoximine (BSO [41]), can induce cell death that is suppressed by $\alpha$-tocopherol and DFO, but not by the caspase inhibitor zVAD-fmk or the necroptosis inhibitor Nec-1 [9, 39]. This suggests that inhibition of GSH synthesis is sufficient to trigger ferroptosis, at least in some cells (Fig. 1). Curiously, however, in many ferroptosis-sensitive cells $\mathrm{BSO}$ is a far less potent inducer of ferroptosis than inhibition of system $x_{\mathrm{c}}^{-}$or GPX4 (J. Cao \& S. Dixon, unpublished). One possibility is that direct GCL inhibition leads to upregulation of an alternative antioxidant pathway that can maintain cell survival in the absence of GSH. For example, high levels of SLC7A11mediated $\mathrm{Cys}_{2}$ import, in conjunction with the GSH-independent thioredoxin (Txn) system, can substitute for the essential function of the GSH-GPX4 lipid peroxide metabolic pathway in some cells both in vitro and in vivo [42-44]. Mechanistically, this might involve the transfer of reducing equivalents from $\mathrm{Cys}_{2}$ to Txn (via thioredoxin reductase) in sufficient quantities to maintain the endogenous lipid antioxidant $\alpha$-tocopherol in a reduced state, and thereby, prevent L-ROS accumulation [45]. Regarding the connection between GSH and cell death, a major issue remaining to be resolved concerns the type of cell death induced by GSH depletion. As described above, in some cells GSH depletion can trigger ferroptosis. However, GSH depletion has also been associated with the induction of apoptosis and sensitization to apoptosisinducing agents (e.g., SMAC mimetics) [46-48]. While more work is required to reconcile the latest findings concerning the role of GSH in ferroptosis with the literature linking GSH depletion and apoptosis, a speculative model is that the depletion of cytosolic GSH promotes ferroptosis, while the depletion of the separate mitochondrial GSH pool promotes, or is more closely associated with, apoptosis [9, 49].

\section{The causes of ferroptotic cell death downstream of GSH depletion and GPX4 inactivation}

In response to system $x_{\mathrm{c}}^{-}$inhibition or GPX4 inactivation, ferroptotic cell death involves the iron-dependent accumulation of L-ROS and the depletion of polyunsaturated fatty acids (PUFAs) [5-7, 9]. L-ROS are typically formed from the PUFA chains of membrane lipids. PUFAs are susceptible to both enzymatic (e.g., lipoxygenase-catalyzed) and non-enzymatic (e.g., ROS-catalyzed) oxidation, leading to the formation of lipid hydroperoxides (L-OOH) [50]. In the presence of iron, L-OOH can form toxic lipid radicals such as the alkoxy radical L-O. These lipid radicals can abstract protons from adjacent PUFAs, initiating a new round of lipid oxidation and further propagation of oxidative damage from one lipid to another [50]. PUFA oxidation and free-radical-mediated damage can ultimately result in PUFA fragmentation into a variety of products [50]. In erastin-treated cancer cells and Gpx4 null mouse cells, L-ROS accumulation, PUFA depletion and cell death are all prevented by treatment with small molecule antioxidants such as Fer-1, suggesting that lipid ROS-mediated damage is essential for ferroptosis [5, 7, 9]. The recently described ferroptosis inhibitor, liproxstatin-1, may also function as a lipophilic antioxidant, although the mechanism of action of this inhibitor has yet to be reported [9].

In cells undergoing ferroptosis the PUFA arachidonic acid (AA) is significantly depleted and AA-derived lipid fragments are detected in the supernatants of $G p x 4^{-1-}$ mouse embryonic fibroblasts (MEFs) [7, 9]. Consistent with a key role for AA in ferroptosis, the deletion of two genes, acyl-CoA synthetase long-chain family member 4 (ACSL4) and lysophosphatidylcholine acyltransferase 3 (LPCAT3), prevents ferroptosis induced by the GPX4 inhibitors RSL3 and ML162 [51]. ACSL4 and LPCAT3 encode enzymes involved in the insertion of AA into membrane phospholipids [52, 53]. This suggests that the execution of ferroptosis can only proceed, following direct 
or indirect (i.e., GSH depletion-induced) inactivation of GPX4, when highly oxidizable PUFAs such as AA are present in the membrane.

The molecular events that occur downstream of PUFA oxidative fragmentation to cause irreversible cell death are unclear. PUFA fragmentation and membrane lipid damage may be sufficient to irreversibly permeabilize the plasma membrane. Alternatively or in parallel, reactive lipid intermediates generated following PUFA oxidation could promote cell death by covalently modifying and inactivating essential intracellular proteins. In support of this possibility, cell lines selected for resistance to ferroptosis overexpress three aldo-keto reductase family 1 , member $\mathrm{C}$ (AKRlC) family members [28]. These proteins can detoxify the toxic reactive lipid intermediate 4-hydroxynonenal (4-HNE), which can be formed downstream of oxidative PUFA fragmentation $[54,55]$. A plausible model is that the activity of AKR1C family members can restrain ferroptosis by preventing the accumulation of 4-HNE to toxic levels, but functional studies are required to investigate this hypothesis in detail.

\section{The role of iron in ferroptosis}

Iron is essential for the execution of ferroptosis. Both membrane permeable (e.g. CPX, 311 and 2,2-BP) and membrane impermeable (e.g. DFO) iron chelators prevent cells from undergoing ferroptosis, whether induced by erastin, RSL3 or a physiological stimulus such as high concentrations of extracellular Glu [5, 6, 17]. Likewise, ferroptosis induced by erastin or $\mathrm{Cys}_{2}$ deprivation is prevented by genetic silencing of $T F R C$, which encodes the transferrin receptor required for the uptake of transferriniron complexes into the cell $[10,17]$. Conversely, supplementing the growth medium with iron-bound transferrin or a bioavailable form of iron (e.g., ferric ammonium citrate), but not other divalent metals, accelerates erastin-induced ferroptosis $[5,10]$. These results firmly establish the need for iron in ferroptosis.

How iron promotes ferroptosis inside the cell remains unclear. Although a redox-independent role for iron cannot formally be ruled out, the most obvious explanation for the ability of iron chelators to block ferroptosis is that they prevent iron from donating electrons to oxygen to form ROS [56]. The properties of different iron chelator classes provide some insights. Lipophilic iron chelators can cross the plasma membrane and chelate the intracellular free, 'redox active' iron pool [57]. This may block death by preventing this iron pool from catalyzing the formation of soluble or lipid radicals that can initiate or propagate oxidative PUFA fragmentation, respectively [50]. Alternatively or in parallel, lipophilic iron chelators may directly inactivate iron-containing enzymes that promote membrane lipid oxidation. In this connection, the lipoxygenase (LOX) family of enzymes are interesting candidates to mediate iron-dependent L-ROS formation. The irondependent LOX enzymes catalyze site-specific oxidation of PUFAs such as AA, and are directly inactivated by lipophilic iron chelators [58-60]. Small molecule LOX inhibitors block cell death due to depletion of GSH or deletion of Gpx4 [39, 61, 62]; however, protection from Gpx4 deletion is not observed when different Lox enzymes are inactivated using genetic reagents individually or in combination [9, 39]. Other iron-dependent enzymes, including the iron and 2-oxoglutarate-dependent dioxygenase prolyl 4-hydroxylase isoform 1 (PHD1) may also be a relevant target of iron chelator action in the prevention of GSH depletion-induced cell death [63]. However, a molecular mechanism linking PHD1 function to the production of L-ROS is less obvious than for LOX enzymes which are known to oxidize PUFAs directly.

Unlike lipophilic iron chelators, DFO is a membrane impermeable iron chelator that accumulates in the lysosome through endocytosis [59]. This suggests that DFO likely prevents ferroptosis by chelating lysosomal iron. However, unlike lethal treatments such as $\mathrm{H}_{2} \mathrm{O}_{2}$, that cause the destruction of the lysosome [64], there is no evidence that ferroptosis-inducing compounds such as erastin trigger lysosomal bursting [7]. Thus, a reasonable model is that DFO, acting within the lysosome, intercepts iron that is ultimately destined for another location in the cell more directly responsible for promoting L-ROS formation (e.g., the 'redox active' pool and/or a specific iron-dependent enzyme).

Iron chelation not only prevents ferroptosis, but also cell death induced by $\mathrm{H}_{2} \mathrm{O}_{2}$ and the synthetic compound artesunate [5]. However, cell death in response to these lethal triggers is typically not blocked by ferroptosis-specific antioxidants such as Fer-1 [5], suggesting that in most cells these agents do not induce ferroptosis per se (but see [65]). Therefore, the combined use of both iron chelators and lipophilic antioxidants is required to definitively assess the role of ferroptosis in a particular lethal phenotype.

\section{Modulators of ferroptosis}

Hypothesis-driven investigations and unbiased loss-offunction genetic screens have identified genes that are essential for, or that modulate the sensitivity to, ferroptosis (Table 3). Ferroptosis was originally characterized through the study of compounds (i.e., erastin, RSL3) that are selectively more lethal to oncogenic RAS mutant cancer cells. Additional RSL compounds have been identified on the basis of this cellular phenotype, and subsequently 
Table 3 Genes and proteins identified as mediators or modulators of ferroptosis

\begin{tabular}{|c|c|c|c|c|}
\hline Gene & $\begin{array}{l}\text { Identification } \\
\text { method }\end{array}$ & Gene product & Gene product function & References \\
\hline TFRC & $\begin{array}{l}\text { Candidate gene, } \\
\text { RNAi }\end{array}$ & Transferrin receptor & Import of transferrin-iron complexes & $\begin{array}{l}\text { Yang and Stockwell } \\
\text { [17], Gao et al. } \\
\text { [10] }\end{array}$ \\
\hline$A C S F 2$ & shRNA screen & Acyl-CoA synthetase family member 2 & Fatty acid metabolism & Dixon et al. [5] \\
\hline $\begin{array}{l}\text { EMC2/ } \\
\quad T T C 35\end{array}$ & shRNA screen & ER membrane protein complex subunit 2 & $\begin{array}{l}\text { Unknown. Possible role in protein } \\
\text { folding in the endoplasmic reticulum }\end{array}$ & Dixon et al. [5] \\
\hline$R P L 8$ & shRNA screen & Ribosomal protein L8 & $\begin{array}{l}\text { Core component of the ribosomal large } \\
\text { subunit involved in protein synthesis. }\end{array}$ & Dixon et al. [5] \\
\hline IREB2 & shRNA screen & Iron-responsive element binding protein 2 & Master regulator of iron homeostasis & Dixon et al. [5] \\
\hline SLC7A11 & $\begin{array}{l}\text { Candidate gene } \\
\text { approach }\end{array}$ & $\begin{array}{l}\text { Solute carrier family } 7 \text { (anionic amino acid } \\
\text { transporter light chain, xc- system), member } \\
11\end{array}$ & Cystine/glutamate antiporter. & Dixon et al. [5] \\
\hline$C S$ & shRNA screen & Citrate synthase & Lipid metabolism & Dixon et al. [5] \\
\hline ATP5G3 & shRNA screen & $\begin{array}{l}\text { ATP synthase, } \mathrm{H}+\text { transporting, mitochondrial } \\
\mathrm{F}_{\mathrm{o}} \text { complex, subunit } \mathrm{C} 3 \text { (subunit } 9 \text { ) }\end{array}$ & $\begin{array}{l}\text { Complex V of mitochondrial } \mathrm{F}_{\mathrm{o}} \mathrm{F}_{1} \\
\text { ATPase; ATP synthesis }\end{array}$ & Dixon et al. [5] \\
\hline$G P X 4$ & $\begin{array}{l}\text { Candidate gene } \\
\text { approach }\end{array}$ & Glutathione peroxidase 4 & Lipid repair & Yang et al. [6] \\
\hline$G C L C$ & $\begin{array}{l}\text { Candidate gene } \\
\text { approach }\end{array}$ & Glutamate-cysteine ligase, catalytic subunit & Glutathione synthesis & Yang et al. [6] \\
\hline ACSLA & $\begin{array}{l}\text { Human haploid } \\
\text { cell genetic } \\
\text { screen }\end{array}$ & $\begin{array}{l}\text { Acyl-CoA synthetase long-chain family } \\
\text { member } 4\end{array}$ & Lipid metabolism & Dixon et al. [51] \\
\hline LPCAT3 & $\begin{array}{l}\text { Human haploid } \\
\text { cell genetic } \\
\text { screen }\end{array}$ & Lysophosphatidylcholine acyltransferase 3 & Lipid metabolism & Dixon et al. [51] \\
\hline $\begin{array}{l}C A R S, \\
\quad E P R S, \\
H A R S\end{array}$ & $\begin{array}{l}\text { Genome-wide } \\
\text { siRNA screen }\end{array}$ & Cysteinyl-tRNA synthetase & Protein translation & Hayano et al. [67] \\
\hline SLC1A5 & $\begin{array}{l}\text { Candidate gene } \\
\text { approach }\end{array}$ & $\begin{array}{l}\text { Solute carrier family } 1 \text { (neutral amino acid } \\
\text { transporter), member } 5\end{array}$ & Glutamine transport & Gao et al. [10] \\
\hline$G L S 2$ & $\begin{array}{l}\text { Candidate gene } \\
\text { approach }\end{array}$ & Glutaminase 2 (liver, mitochondrial) & Glutaminolysis & Gao et al. [10] \\
\hline GOT1 & $\begin{array}{l}\text { Candidate gene } \\
\text { approach }\end{array}$ & Glutamic-oxaloacetic transaminase 1 , soluble & Glutaminolysis & Gao et al. [10] \\
\hline HSPB1 & $\begin{array}{l}\text { Candidate gene } \\
\text { approach }\end{array}$ & Heat shock $27 \mathrm{kDa}$ protein 1 & Protein folding; iron metabolism & Sun et al. [87] \\
\hline TP53 & $\begin{array}{l}\text { Candidate gene } \\
\text { approach }\end{array}$ & Tumor protein $\mathrm{p} 53$ & Tumor suppressor, metabolic regulator & Jiang et al. [11] \\
\hline
\end{tabular}

confirmed to trigger ferroptosis (e.g. [6, 16]). These results suggest a relationship between ferroptosis and oncogenic RAS activity, at least in certain cells. In KRAS-mutant Calu-1 lung cancer cells shRNA-mediated silencing of $K R A S$ reduces sensitivity to erastin [13]. Silencing of oncogenic mutant BRAF in A-673 cells also reduces sensitivity to erastin [13], suggesting that the activity of the broader RAS-RAF-MEK pathway could determine ferroptosis sensitivity in individual cell lines. Constitutive RAS pathway activity can promote the expression of TFRC and suppress the expression of iron storage proteins in engineered tumor cell lines, providing one explanation for how oncogenic RAS activity could promote sensitivity to ferroptosis [17]. However, this model remains to be tested in additional cell types.

The link between RAS pathway activity and ferroptosis is complicated by two observations. First, when comparing profiles of erastin sensitivity across a panel of 117 cancer cell lines, RAS-mutant cancer cell lines are on average no more sensitive to ferroptosis-inducing compounds than cancer cells expressing wild-type RAS [6]. In fact, for unknown reasons, diffuse large B cell lymphoma (DLBCL) and renal cell carcinoma cancer cell lines, which do not typically contain RAS pathway mutations, emerge as the most sensitive types of cancer cells [6]. Second, RMS13 rhabdomyosarcoma cells overexpressing oncogenic $H R A S$, 
Table 4 Known and suspected physiological or pathological ferroptosis-inducing conditions

\begin{tabular}{|c|c|c|c|}
\hline Treatment & System & Observation & References \\
\hline Glutamate & $\begin{array}{l}\text { Rat postnatal hippocampal } \\
\text { slice culture }\end{array}$ & $\begin{array}{l}\text { Death suppressed by Fer-1, } \\
\text { CPX }\end{array}$ & Dixon et al. [5] \\
\hline Cystine deprivation & $\begin{array}{l}\text { Rat postnatal pre- } \\
\text { oligodendrocyte cultures }\end{array}$ & Death suppressed by Fer-1 & Skouta et al. [7] \\
\hline $\begin{array}{l}\text { Huntington gene fragment } \\
\text { overexpression }\end{array}$ & $\begin{array}{l}\text { Transfected postnatal } \\
\text { corticostrial rat brain slice }\end{array}$ & Death suppressed by Fer-1 & Skouta et al. [7] \\
\hline Iron overload & $\begin{array}{l}\text { Mouse kidney proximal } \\
\text { tubules }\end{array}$ & Death suppressed by Fer-1 & Skouta et al. [7] \\
\hline Acetaminophen & Mouse hepatocytes & Death suppressed by Fer-1 & Lörincz et al. [88] \\
\hline Gpx4 deletion & $\begin{array}{l}\text { MEFs, mouse kidney cells, } \\
\text { mouse T cells }\end{array}$ & $\begin{array}{l}\text { Rapid death, suppressed by } \\
\text { vitamin E, Fer-1 }\end{array}$ & $\begin{array}{l}\text { Friedmann Angeli et al. [9], Matsushita } \\
\text { et al. [89], Seiler et al. [39] }\end{array}$ \\
\hline p53 upregulation & MEFs & $\begin{array}{l}\text { p53 upregulation leads to } \\
\text { sensitization to ferroptosis }\end{array}$ & Jiang et al. [11] \\
\hline Ischemia/reperfusion & $\begin{array}{l}\text { Mouse kidney (in vivo), } \\
\text { mouse heart (ex vivo) }\end{array}$ & $\begin{array}{l}\text { Death suppressed by Fer-1 } \\
\text { analogs, iron chelation }\end{array}$ & Gao et al. [10], Linkermann et al. [8] \\
\hline $\begin{array}{l}\text { Amino acid deprivation in } \\
\text { presence of serum and glucose }\end{array}$ & MEFs & Death suppressed by Fer-1 & Gao et al. [10] \\
\hline
\end{tabular}

MEFs mouse embryonic fibroblasts, $\beta-M E$ beta-mercaptoethanol

KRAS or NRAS are resistant to erastin and RSL3 [66]. A reasonable explanation for this confusing picture is that the effects of RAF-MEK-ERK pathway activity on ferroptosis differ depending on cell lineage or mutant RAS protein expression levels. The discovery of biomarkers that more universally predict sensitivity and resistance to ferroptosis would help guide the development of these agents for cancer treatment.

In addition to RAS pathway components, additional genes have been found to modulate ferroptosis (see Table 3). These genes can be linked to processes known to be essential for ferroptosis, including iron metabolism (TFRC, IREB2, HSPB1), protein synthesis (RPL8) and lipid metabolism (ACSF2, ACSL4, LPCAT3, and possibly $C S$ ). Silencing of $C A R S$, and certain other tRNA synthetases (HARS, EPRS), appears to promote cell survival indirectly, by enhancing the synthesis of Cys from methionine, via the transsulfuration pathway, allowing the cell to maintain GSH synthesis when system $x_{\mathrm{c}}^{-}$is blocked by erastin [67]. SLC1A5, GLS2 and GOT1 are required for glutamine uptake and metabolism to Glu and, ultimately, $\alpha$-ketoglutarate [10]. The role of Gln metabolism in ferroptosis is not clear, although this pathway may contribute to the formation of oxidizable membrane lipids by feeding precursors (i.e., citrate) towards fatty acid or lipid synthesis [5]. The role of other genes (ATP5G3, EMC2/TTC35) in ferroptosis has yet to be studied in detail.

Another recently described modulator of ferroptosis is p53, encoded by TP53. Using a p53-inducible cell line, p53 upregulation was shown to repress expression of the system $x_{\mathrm{c}}^{-}$transporter subunit SLC7A11 and sensitize cells to ferroptosis [11]. Chromatin immunoprecipitation and electrophoretic mobility shift analysis experiments suggest that p53 binds to the SLC7A11 locus at a specific p53 response element within the 5' untranslated region. At this site, p53 presumably recruits chromatin-modifying enzymes that repress SLC7A11 transcription. These results are of great interest since the mechanism of p53-mediated tumor suppression remains highly controversial. While early literature suggested that p53-dependent tumor suppression involved the induction of cell cycle arrest, senescence or apoptosis, the recent analysis of several transactivation-defective p53 mutants has called this model into question and it now appears that alterations in intracellular metabolism may account for the ability of p53 to suppress tumor formation [68-70]. p53-dependent effects on SLC7A11-mediated Cys uptake fit within this emerging picture of p53-dependent metabolic modulation, although it should be noted that SLC7A11 was not identified in other comprehensive studies of genomic p53 binding sites and direct p53 transcriptional targets [71, 72]. Moreover, p53 is known to induce the expression of a number of antioxidant genes that would be predicted to suppress ROS accumulation, and therefore counteract ferroptosis [70]. Resolving the role of p53 in ferroptosis promises to be an active area of investigation.

\section{The role of ferroptosis in pathological cell death}

A role for ferroptosis has been found in a growing number of pathological cell death scenarios (Table 4). These studies have been enabled by the discovery of novel small 
molecules, including Fer-1 [5], improved Fer-1 analogs [7, 8] and liproxstatin-1 [9], that potently and specifically block ferroptosis. In a rat hippocampal slice culture model, exposure to high concentrations of Glu triggers substantial cell death that can be significantly attenuated by both Fer-1 and the iron chelator CPX [5]. Complete protection from cell death is observed with Fer-1 and several Fer-1 analogs in rat oligodendrocytes deprived of $\mathrm{Cys}_{2}$, a model of the pathological process leading to periventricular leukomalacia, while more modest protection is observed in a model of Huntington's disease and in a model of iron-induced kidney tubule damage [7]. Fer-1 and improved analogs also protect isolated renal tubules from erastin-induced cell death, reduce kidney injury following acute oxalate-induced damage, and protect from acute renal failure and organ damage in a model of severe kidney ischemia/ reperfusion injury [8]. In a similar vein, the novel ferroptosis inhibitor liproxstatin-1 attenuates cell death in, and extends survival of, mice in which Gpx4 is selectively deleted from the kidney [9]. Finally, both DFO and the glutaminolysis inhibitor Compound 968 prevent cell death in an ex vivo model of ischemia/reperfusion injury in the mouse heart [10]. While these results are suggestive of ferroptosis in this pathological scenario, further work using ferroptosis-specific inhibitors such as Fer-1 will be helpful to confirm this point.

These studies suggest a number of tissues and scenarios where the induction of ferroptosis may contribute to pathological cell death. One concern with the ex vivo model studies is that ambient levels of oxygen $\left(\mathrm{O}_{2}\right.$, i.e., $21 \%)$ artificially enhances any oxidative cell death process under consideration. While this cannot be completely ruled out, studies of mouse and human cells show that both erastin treatment and Gpx4 inactivation trigger ferroptosis with similar inhibition profiles and cell death phenotypes at both ambient (i.e., $21 \%$ ) and physiological $(<5 \%)$ levels of $\mathrm{O}_{2}$, suggesting that ferroptotic mechanisms remain active in low oxygen conditions [28, 39]. A second concern associated with these studies is that it is impossible to know, with certainty, that Fer-1 and other inhibitors are blocking ferroptosis and not another form of cell death. This is because we currently lack suitable molecular markers of ferroptosis that would identify cells undergoing this process, prior to death. While the mRNA expression levels of two genes prostaglandin E synthase 2 (PTGES2) and ChaC glutathionespecific gamma-glutamylcyclotransferase 1 (CHACl) are significantly elevated in cells undergoing ferroptosis $[6$, 28], these are not suitable for use in live cells or intact tissues. Further work is needed to identify additional ferroptotic markers that could be used for future in vivo studies.



Fig. 3 The relationship between iron, diatomic oxygen $\left(\mathrm{O}_{2}\right)$, PUFAs and glutathione $(\mathrm{GSH})$. Iron $\left(\mathrm{Fe}^{2+}\right), \mathrm{O}_{2}$ and PUFAs are each, individually, required for cell growth and survival (green arrows). GSH is also required for cell growth and proliferation, as well as to prevent the combination of $\mathrm{Fe}^{2+}, \mathrm{O}_{2}$ and PUFAs from triggering ferroptosis

\section{Ferroptosis and oxidative glutamate toxicity}

Ferroptosis appears similar in several respects to oxidative glutamate toxicity (OGT), a phenotype observed in certain neuronal cell lines treated with high concentration of Glu to inactivate system $x_{\mathrm{c}}^{-}$and deprive the cell of $\mathrm{Cys}_{2}$ (e.g. [25, 73-75]). Both erastin-induced ferroptosis and OGT involve GSH depletion, L-ROS accumulation and cell death that can be blocked by lipophilic antioxidants including Fer-1 $[5,25,62,73,76,77]$. However, as discussed previously (see $[5,56]$ ), a number of key differences between ferroptosis and OGT are apparent, downstream of L-ROS accumulation. For example, in OGT, but not ferroptosis, extracellular $\mathrm{Ca}^{2+}$ influx, BH3 interacting domain death agonist (Bid)-mediated mitochondrial damage and nuclear translocation of apoptosis inducing factor 1 (AIF1) are essential for death $[62,73,78]$. Thus, while ferroptosis and OGT can share a common mechanism of initiation (i.e. $\mathrm{Cys}_{2}$ deprivation), the terminal phases of death execution appear to be more complex and elaborate in cells undergoing OGT. Of note, AIF1 is reportedly essential for cell death in MEFs lacking Gpx4 [39], although this result remains to be confirmed in other cells. Whether ferroptosis is an abbreviated form of OGT specific to cancer cells, or whether OGT is a more elaborate form of ferroptosis specific to neuronal cells, remains to be resolved.

\section{Conclusions and perspectives}

Ferroptosis lies at the nexus of essential biological processes involving $\mathrm{O}_{2}$, iron and PUFAs. $\mathrm{O}_{2}$, iron and PUFAs are, individually, essential for cell growth and proliferation. However, the interaction between $\mathrm{O}_{2}$, iron and PUFAs can lead to the accumulation of toxic levels of L-ROS. Thus, ferroptosis results from an imbalance between $\mathrm{O}_{2}$-dependent, iron-catalyzed, L-ROS production and GSH- 
dependent GPX4 activity (Fig. 3). Compared to other forms of RCD, the 'logic' of the ferroptosis pathway is unique. Apoptosis, for example, is triggered by diverse lethal stimuli (e.g. DNA damage, protein misfolding, etc.) leading to activation of a latent, pro-death enzymatic program and the ordered disassembly of the cell. Ferroptosis, by contrast, results from the inactivation of an essential metabolic process, leading to an iron-catalyzed, L-ROSmediated cellular collapse. It has been noted by Green and Victor that ferroptosis is therefore best described as a form of cellular 'sabotage', wherein the normal metabolic functions of the cell contribute to cell death [79]. This distinguishes ferroptosis from apoptosis and other forms of RCD that are best described as 'cell suicide' [79]. Whether the inactivation of any other essential metabolic processes can trigger ferroptosis, or perhaps other novel cell sabotage programs, is unknown.

The distinction between ferroptosis as a form of cell sabotage and apoptosis as a form of cell suicide is intriguing, but begs the question of why cell sabotage might exist in the first place. Why does GSH depletion and GPX4 inactivation not simply trigger apoptosis? Is there something unique about GSH depletion and/or GPX4 inactivation that would make an alternative form of death like ferroptosis inevitable? One possibility is that GSH is required for the execution of apoptosis and that GSH depletion therefore inhibits the apoptotic program. While certain cancer cells treated with BSO (to deplete GSH) are unable to activate apoptosis in response to lethal doses of various alkylating agents, GSH is apparently not required for apoptotic cell death in response to most lethal triggers $[80,81]$. Thus, it seems that cells depleted of GSH are fully capable of undergoing apoptosis, and yet still typically adopt a ferroptotic fate.

An alternative model is that GSH depletion is 'insulated' from the apoptotic pathway to enable it to produce a specific, adaptive cellular phenotype. In cells undergoing ferroptosis caspases are not activated [13] and dying cells are therefore likely to release a number of immune modulators [8]. This may be beneficial if the goal is to trigger an immune response. Interestingly, the system $x_{\mathrm{c}}^{-}$transporter SLC7A11 is required for entry of Kaposi's sarcomaassociated herpesvirus into certain cells [82], a process likely to disrupt normal glutathione homeostasis. Likewise infection of immune cells with the human immunodeficiency virus type-1 (HIV-1) is well know to cause dysregulation of glutathione homeostasis [83, 84], possibly enhancing sensitivity to ferroptosis. Thus, ferroptosis may be a fate preferentially adopted by certain immune cells, in response to infection, to ensure the release of appropriate immunostimulatory signals. More broadly, low levels of intracellular Cys and GSH may be sensed, like ATP and acetyl-CoA, as indicators of poor cell health and constitute a novel 'metabolic checkpoint' [85]. Cells with low levels of antioxidant defenses accumulate DNA damage more readily [86] and in multicellular organisms it could, therefore, be adaptive to have a specific route available for these cells to be eliminated. Future studies of ferroptosis promise to illuminate these and other questions surrounding this intriguing cell death process.

Acknowledgments We thank members of the Dixon lab for comments on this manuscript. This work was supported by funding from the Stanford Chemistry Engineering and Medicine for Human Health (ChEM-H) initiative to J.Y.C. and an R00 award (R00CA166517) to S.J.D. from the National Cancer Institute (USA).

Open Access This article is distributed under the terms of the Creative Commons Attribution 4.0 International License (http:// creativecommons.org/licenses/by/4.0/), which permits unrestricted use, distribution, and reproduction in any medium, provided you give appropriate credit to the original author(s) and the source, provide a link to the Creative Commons license, and indicate if changes were made.

\section{References}

1. Brennan MA, Cookson BT (2000) Salmonella induces macrophage death by caspase-1-dependent necrosis. Mol Microbiol 38:31-40

2. Degterev A, Huang Z, Boyce M et al (2005) Chemical inhibitor of nonapoptotic cell death with therapeutic potential for ischemic brain injury. Nat Chem Biol 1:112-119. doi:10.1038/ nchembio711

3. Fuchs Y, Steller H (2011) Programmed cell death in animal development and disease. Cell 147:742-758. doi:10.1016/j.cell. 2011.10.033

4. Liu Y, Shoji-Kawata S, Sumpter RM et al (2013) Autosis is a $\mathrm{Na}^{+}, \mathrm{K}^{+}$-ATPase-regulated form of cell death triggered by autophagy-inducing peptides, starvation, and hypoxia-ischemia. Proc Natl Acad Sci USA 110:20364-20371. doi:10.1073/pnas. 1319661110

5. Dixon SJ, Lemberg KM, Lamprecht MR et al (2012) Ferroptosis: an iron-dependent form of nonapoptotic cell death. Cell 149:1060-1072. doi:10.1016/j.cell.2012.03.042

6. Yang WS, SriRamaratnam R, Welsch ME et al (2014) Regulation of ferroptotic cancer cell death by GPX4. Cell 156:317-331. doi:10.1016/j.cell.2013.12.010

7. Skouta R, Dixon SJ, Wang J et al (2014) Ferrostatins inhibit oxidative lipid damage and cell death in diverse disease models. J Am Chem Soc 136:4551-4556. doi:10.1021/ja411006a

8. Linkermann A, Skouta R, Himmerkus N et al (2014) Synchronized renal tubular cell death involves ferroptosis. Proc Natl Acad Sci USA 111:16836-16841. doi:10.1073/pnas.1415518111

9. Friedmann Angeli JP, Schneider M, Proneth B et al (2014) Inactivation of the ferroptosis regulator $\mathrm{Gpx} 4$ triggers acute renal failure in mice. Nat Cell Biol 16:1180-1191. doi:10.1038/ ncb3064

10. Gao M, Monian P, Quadri N et al (2015) Glutaminolysis and Transferrin Regulate Ferroptosis. Mol Cell 59:298-308. doi:10. 1016/j.molcel.2015.06.011

11. Jiang L, Kon N, Li T et al (2015) Ferroptosis as a p53-mediated activity during tumour suppression. Nature 520:57-62. doi:10. 1038/nature14344 
12. Dolma S, Lessnick SL, Hahn WC, Stockwell BR (2003) Identification of genotype-selective antitumor agents using synthetic lethal chemical screening in engineered human tumor cells. Cancer Cell 3:285-296

13. Yagoda N, von Rechenberg M, Zaganjor E et al (2007) RASRAF-MEK-dependent oxidative cell death involving voltagedependent anion channels. Nature 447:864-868. doi:10.1038/ nature 05859

14. Torrance CJ, Agrawal V, Vogelstein B, Kinzler KW (2001) Use of isogenic human cancer cells for high-throughput screening and drug discovery. Nat Biotechnol 19:940-945. doi:10.1038/ nbt1001-940

15. Shaw AT, Winslow MM, Magendantz M et al (2011) Selective killing of K-ras mutant cancer cells by small molecule inducers of oxidative stress. Proc Natl Acad Sci USA 108:8773-8778. doi:10. 1073/pnas. 1105941108

16. Weiwer M, Bittker J, Lewis TA et al (2012) Development of small-molecule probes that selectively kill cells induced to express mutant RAS. Bioorg Med Chem Lett 22:1822-1826. doi:10.1016/j.bmcl.2011.09.047

17. Yang WS, Stockwell BR (2008) Synthetic lethal screening identifies compounds activating iron-dependent, nonapoptotic cell death in oncogenic-RAS-harboring cancer cells. Chem Biol 15:234-245. doi:10.1016/j.chembiol.2008.02.010

18. Wolpaw AJ, Shimada K, Skouta R et al (2011) Modulatory profiling identifies mechanisms of small molecule-induced cell death. Proc Natl Acad Sci USA 108:E771-E780. doi:10.1073/ pnas. 1106149108

19. Eagle H (1955) Nutrition needs of mammalian cells in tissue culture. Science 122:501-514

20. Eagle H (1959) Amino acid metabolism in mammalian cell cultures. Science 130:432-437

21. Eagle H, Piez KA, Oyama VI (1961) The biosynthesis of cystine in human cell cultures. J Biol Chem 236:1425-1428

22. Bannai S, Tsukeda H, Okumura H (1977) Effect of antioxidants on cultured human diploid fibroblasts exposed to cystine-free medium. Biochem Biophys Res Commun 74:1582-1588

23. Yonezawa M, Back SA, Gan X et al (1996) Cystine deprivation induces oligodendroglial death: rescue by free radical scavengers and by a diffusible glial factor. J Neurochem 67:566-573

24. De Brabander M, Van Belle H, Aerts F et al (1979) Protective effect of levamisole and its sulfhydryl metabolite OMPI against cell death induced by glutathione depletion. Int $\mathrm{J}$ Immunopharmacol 1:93-100

25. Murphy TH, Miyamoto M, Sastre A et al (1989) Glutamate toxicity in a neuronal cell line involves inhibition of cystine transport leading to oxidative stress. Neuron 2:1547-1558

26. Murphy TH, Schnaar RL, Coyle JT (1990) Immature cortical neurons are uniquely sensitive to glutamate toxicity by inhibition of cystine uptake. FASEB J 4:1624-1633

27. Bauer AJ, Gieschler S, Lemberg KM et al (2011) Functional model of metabolite gating by human voltage-dependent anion channel 2. Biochemistry 50:3408-3410. doi:10.1021/bi2003247

28. Dixon SJ, Patel DN, Welsch M et al (2014) Pharmacological inhibition of cystine-glutamate exchange induces endoplasmic reticulum stress and ferroptosis. Elife 3:e02523. doi:10.7554/ eLife. 02523

29. Sato H, Tamba M, Ishii T, Bannai S (1999) Cloning and expression of a plasma membrane cystine/glutamate exchange transporter composed of two distinct proteins. J Biol Chem 274:11455-11458

30. Gout PW, Buckley AR, Simms CR, Bruchovsky N (2001) Sulfasalazine, a potent suppressor of lymphoma growth by inhibition of the $\mathrm{x}(\mathrm{c})$ - cystine transporter: a new action for an old drug. Leukemia 15:1633-1640
31. Ishii T, Bannai S, Sugita Y (1981) Mechanism of growth stimulation of L1210 cells by 2-mercaptoethanol in vitro. Role of the mixed disulfide of 2-mercaptoethanol and cysteine. J Biol Chem 256:12387-12392

32. Larraufie M-H, Yang WS, Jiang E et al (2015) Incorporation of metabolically stable ketones into a small molecule probe to increase potency and water solubility. Bioorg Med Chem Lett. doi:10.1016/j.bmcl.2015.07.018

33. Lachaier E, Louandre C, Godin C et al (2014) Sorafenib induces ferroptosis in human cancer cell lines originating from different solid tumors. Anticancer Res 34:6417-6422

34. Louandre C, Ezzoukhry Z, Godin C et al (2013) Iron-dependent cell death of hepatocellular carcinoma cells exposed to sorafenib. Int J Cancer 133:1732-1742. doi:10.1002/ijc.28159

35. Panka DJ, Wang W, Atkins MB, Mier JW (2006) The Raf inhibitor BAY 43-9006 (Sorafenib) induces caspase-independent apoptosis in melanoma cells. Cancer Res 66:1611-1619. doi:10. 1158/0008-5472.CAN-05-0808

36. Coriat R, Nicco C, Chéreau C et al (2012) Sorafenib-induced hepatocellular carcinoma cell death depends on reactive oxygen species production in vitro and in vivo. Mol Cancer Ther 11:2284-2293. doi:10.1158/1535-7163.MCT-12-0093

37. Liu L, Cao Y, Chen C et al (2006) Sorafenib blocks the RAF/ MEK/ERK pathway, inhibits tumor angiogenesis, and induces tumor cell apoptosis in hepatocellular carcinoma model PLC/ PRF/5. Cancer Res 66:11851-11858. doi:10.1158/0008-5472. CAN-06-1377

38. Ursini F, Maiorino M, Gregolin C (1985) The selenoenzyme phospholipid hydroperoxide glutathione peroxidase. Biochim Biophys Acta 839:62-70

39. Seiler A, Schneider M, Förster H et al (2008) Glutathione peroxidase 4 senses and translates oxidative stress into 12/15lipoxygenase dependent- and AIF-mediated cell death. Cell Metab 8:237-248. doi:10.1016/j.cmet.2008.07.005

40. Woo JH, Shimoni Y, Yang WS et al (2015) Elucidating Compound Mechanism of Action by Network Perturbation Analysis. Cell 162:441-451. doi:10.1016/j.cell.2015.05.056

41. Griffith OW, Meister A (1979) Potent and specific inhibition of glutathione synthesis by buthionine sulfoximine (S-n-butyl homocysteine sulfoximine). J Biol Chem 254:7558-7560

42. Mandal PK, Seiler A, Perisic T et al (2010) System x(c)- and thioredoxin reductase 1 cooperatively rescue glutathione deficiency. J Biol Chem 285:22244-22253. doi:10.1074/jbc.M110. 121327

43. Banjac A, Perisic T, Sato H et al (2008) The cystine/cysteine cycle: a redox cycle regulating susceptibility versus resistance to cell death. Oncogene 27:1618-1628. doi:10.1038/sj.onc.1210796

44. Harris IS, Treloar AE, Inoue S et al (2015) Glutathione and Thioredoxin Antioxidant Pathways Synergize to Drive Cancer Initiation and Progression. Cancer Cell 27:211-222. doi:10.1016/ j.ccell.2014.11.019

45. May JM, Morrow JD, Burk RF (2002) Thioredoxin reductase reduces lipid hydroperoxides and spares alpha-tocopherol. Biochem Biophys Res Commun 292:45-49

46. Franco R, Cidlowski JA (2009) Apoptosis and glutathione: beyond an antioxidant. Cell Death Differ 16:1303-1314. doi:10. 1038/cdd.2009.107

47. Savaskan NE, Borchert A, Bräuer AU, Kuhn H (2007) Role for glutathione peroxidase- 4 in brain development and neuronal apoptosis: specific induction of enzyme expression in reactive astrocytes following brain injury. Free Radic Biol Med 43:191-201. doi:10.1016/j.freeradbiomed.2007.03.033

48. Schoeneberger H, Belz K, Schenk B, Fulda S (2015) Impairment of antioxidant defense via glutathione depletion sensitizes acute lymphoblastic leukemia cells for Smac mimetic-induced cell death. Oncogene 34:4032-4043. doi:10.1038/onc.2014.338 
49. Macho A, Hirsch T, Marzo I et al (1997) Glutathione depletion is an early and calcium elevation is a late event of thymocyte apoptosis. J Immunol 158:4612-4619

50. Cheng Z, Li Y (2007) What is responsible for the initiating chemistry of iron-mediated lipid peroxidation: an update. Chem Rev 107:748-766. doi:10.1021/cr040077w

51. Dixon SJ, Winter GE, Musavi LS et al (2015) Human Haploid Cell Genetics Reveals Roles for Lipid Metabolism Genes in Nonapoptotic Cell Death. ACS Chem Biol 10:1604-1609. doi:10. 1021/acschembio.5b00245

52. Soupene E, Kuypers FA (2008) Mammalian long-chain acyl-CoA synthetases. Exp Biol Med (Maywood) 233:507-521. doi:10. 3181/0710-MR-287

53. Shindou H, Shimizu T (2009) Acyl-CoA:lysophospholipid acyltransferases. J Biol Chem 284:1-5. doi:10.1074/jbc.R800046200

54. Burczynski ME, Sridhar GR, Palackal NT, Penning TM (2001) The reactive oxygen species-and Michael acceptor-inducible human aldo-keto reductase $\mathrm{AKR} 1 \mathrm{C} 1$ reduces the alpha, betaunsaturated aldehyde 4-hydroxy-2-nonenal to 1,4-dihydroxy-2nonene. J Biol Chem 276:2890-2897. doi:10.1074/jbc. M006655200

55. Schneider C, Porter NA, Brash AR (2008) Routes to 4-hydroxynonenal: fundamental issues in the mechanisms of lipid peroxidation. J Biol Chem 283:15539-15543. doi:10.1074/jbc. R800001200

56. Dixon SJ, Stockwell BR (2014) The role of iron and reactive oxygen species in cell death. Nat Chem Biol 10:9-17. doi:10. 1038/nchembio. 1416

57. Petrat F, de Groot H, Rauen U (2001) Subcellular distribution of chelatable iron: a laser scanning microscopic study in isolated hepatocytes and liver endothelial cells. Biochem J 356:61-69

58. Kuhn H, Banthiya S, van Leyen K (2015) Mammalian lipoxygenases and their biological relevance. Biochim Biophys Acta 1851:308-330. doi:10.1016/j.bbalip.2014.10.002

59. Barradas MA, Jeremy JY, Kontoghiorghes GJ et al (1989) Iron chelators inhibit human platelet aggregation, thromboxane A2 synthesis and lipoxygenase activity. FEBS Lett 245:105-109

60. Abeysinghe RD, Roberts PJ, Cooper CE et al (1996) The environment of the lipoxygenase iron binding site explored with novel hydroxypyridinone iron chelators. J Biol Chem 271:7965-7972

61. Wang H, Li J, Follett PL et al (2004) 12-Lipoxygenase plays a key role in cell death caused by glutathione depletion and arachidonic acid in rat oligodendrocytes. Eur $\mathrm{J}$ Neurosci 20:2049-2058. doi:10.1111/j.1460-9568.2004.03650.x

62. Li Y, Maher P, Schubert D (1997) A role for 12-lipoxygenase in nerve cell death caused by glutathione depletion. Neuron 19:453-463

63. Siddiq A, Aminova LR, Troy CM et al (2009) Selective inhibition of hypoxia-inducible factor (HIF) prolyl-hydroxylase 1 mediates neuroprotection against normoxic oxidative death via HIF- and CREB-independent pathways. J Neurosci 29:8828-8838. doi:10.1523/JNEUROSCI.1779-09.2009

64. Kurz T, Gustafsson B, Brunk UT (2006) Intralysosomal iron chelation protects against oxidative stress-induced cellular damage. FEBS J 273:3106-3117. doi:10.1111/j.1742-4658.2006. 05321.x

65. Eling N, Reuter L, Hazin J et al (2015) Identification of artesunate as a specific activator of ferroptosis in pancreatic cancer cells. Oncoscience 2:517-532

66. Schott C, Graab U, Cuvelier N et al (2015) Oncogenic RAS Mutants Confer Resistance of RMS13 Rhabdomyosarcoma Cells to Oxidative Stress-Induced Ferroptotic Cell Death. Front Oncol 5:131. doi:10.3389/fonc.2015.00131

67. Hayano M, Yang WS, Corn CK et al (2015) Loss of cysteinyltRNA synthetase (CARS) induces the transsulfuration pathway and inhibits ferroptosis induced by cystine deprivation. Cell Death Differ. doi:10.1038/cdd.2015.93

68. Li T, Kon N, Jiang L et al (2012) Tumor suppression in the absence of p53-mediated cell-cycle arrest, apoptosis, and senescence. Cell 149:1269-1283. doi:10.1016/j.cell.2012.04.026

69. Brady CA, Jiang D, Mello SS et al (2011) Distinct p53 transcriptional programs dictate acute DNA-damage responses and tumor suppression. Cell 145:571-583. doi:10.1016/j.cell.2011.03. 035

70. Bieging KT, Mello SS, Attardi LD (2014) Unravelling mechanisms of p53-mediated tumour suppression. Nat Rev Cancer 14:359-370. doi: $10.1038 / \mathrm{nrc} 3711$

71. Allen MA, Andrysik Z, Dengler VL et al (2014) Global analysis of p53-regulated transcription identifies its direct targets and unexpected regulatory mechanisms. Elife 3:e02200. doi:10.7554/ eLife.02200

72. Kenzelmann Broz D, Spano Mello S, Bieging KT et al (2013) Global genomic profiling reveals an extensive p53-regulated autophagy program contributing to key p53 responses. Genes Dev 27:1016-1031. doi:10.1101/gad.212282.112

73. Tobaben S, Grohm J, Seiler A et al (2011) Bid-mediated mitochondrial damage is a key mechanism in glutamate-induced oxidative stress and AIF-dependent cell death in immortalized HT-22 hippocampal neurons. Cell Death Differ 18:282-292. doi:10.1038/cdd.2010.92

74. Albrecht P, Lewerenz J, Dittmer S et al (2010) Mechanisms of oxidative glutamate toxicity: the glutamate/cystine antiporter system xc- as a neuroprotective drug target. CNS Neurol Disord: Drug Targets 9:373-382

75. Tan S, Schubert D, Maher P (2001) Oxytosis: a novel form of programmed cell death. Curr Top Med Chem 1:497-506

76. Tan S, Wood M, Maher P (1998) Oxidative stress induces a form of programmed cell death with characteristics of both apoptosis and necrosis in neuronal cells. J Neurochem 71:95-105

77. Liu Y, Wang W, Li Y et al (2015) The 5-Lipoxygenase Inhibitor Zileuton Confers Neuroprotection against Glutamate Oxidative Damage by Inhibiting Ferroptosis. Biol Pharm Bull 38:1234-1239. doi:10.1248/bpb.b15-00048

78. Henke N, Albrecht P, Bouchachia I et al (2013) The plasma membrane channel ORAI1 mediates detrimental calcium influx caused by endogenous oxidative stress. Cell Death Dis 4:e470. doi: $10.1038 /$ cddis. 2012.216

79. Green DR, Victor B (2012) The pantheon of the fallen: why are there so many forms of cell death? Trends Cell Biol 22:555-556. doi:10.1016/j.tcb.2012.08.008

80. Troyano A, Fernández C, Sancho P et al (2001) Effect of glutathione depletion on antitumor drug toxicity (apoptosis and necrosis) in U-937 human promonocytic cells. The role of intracellular oxidation. J Biol Chem 276:47107-47115. doi:10. 1074/jbc.M104516200

81. Fernandes RS, Cotter TG (1994) Apoptosis or necrosis: intracellular levels of glutathione influence mode of cell death. Biochem Pharmacol 48:675-681

82. Dai L, Noverr MC, Parsons C et al (2015) xCT, not just an amino-acid transporter: a multi-functional regulator of microbial infection and associated diseases. Front Microbiol 6:120. doi:10. 3389/fmicb.2015.00120

83. Herzenberg LA, De Rosa SC, Dubs JG et al (1997) Glutathione deficiency is associated with impaired survival in HIV disease. Proc Natl Acad Sci USA 94:1967-1972

84. Bhaskar A, Munshi M, Khan SZ et al (2015) Measuring glutathione redox potential of HIV-1-infected macrophages. J Biol Chem 290:1020-1038. doi:10.1074/jbc.M114.588913

85. Green DR, Galluzzi L, Kroemer G (2014) Cell biology. Metabolic control of cell death. Science 345:1250256. doi:10.1126/ science. 1250256 
86. Gokce G, Ozsarlak-Sozer G, Oktay G et al (2009) Glutathione depletion by buthionine sulfoximine induces oxidative damage to DNA in organs of rabbits in vivo. Biochemistry 48:4980-4987. doi:10.1021/bi900030z

87. Sun X, Ou Z, Xie M et al (2015) HSPB1 as a novel regulator of ferroptotic cancer cell death. Oncogene. doi:10.1038/onc.2015.32
88. Lőrincz T, Jemnitz K, Kardon T et al (2015) Ferroptosis is involved in acetaminophen induced cell death. Pathol Oncol Res 1-7. doi:10.1007/s12253-015-9946-3

89. Matsushita M, Freigang S, Schneider C et al (2015) T cell lipid peroxidation induces ferroptosis and prevents immunity to infection. J Exp Med 212:555-568. doi:10.1084/jem.20140857 